\title{
Indigenous Women Managing Pregnancy Complications in Rural Ecuador
}

\author{
Barriers and Opportunities to Enhance Antenatal Care
}

\author{
Nervo Verdezoto \\ School of Computer Science and \\ Informatics, Cardiff University, \\ Cardiff, UK \\ verdezotodiasn@cardiff.ac.uk \\ Nicola Mackintosh \\ Department of Health Sciences, \\ University of Leicester, Leicester, UK \\ nicola.mackintosh@leicester.ac.uk
}

\author{
Francisca Carpio-Arias \\ Instituto Tecnológico José Ortega y \\ Gasset, Riobamba, Ecuador \\ antito084@hotmail.com
}

\author{
Parisa Eslambolchilar \\ School of Computer Science and \\ Informatics, Cardiff University, \\ United Kingdom \\ eslambolchilarp@cardiff.ac.uk
}

\author{
Valeria Carpio-Arias \\ School of Public Health, Escuela \\ Superior Politécnica de Chimborazo, \\ ESPOCH, Riobamba, Ecuador \\ tannia.carpio@espoch.edu.ec \\ Verónica Delgado \\ School of Public Health, Escuela \\ Superior Politécnica de Chimborazo, \\ ESPOCH, Riobamba, Ecuador \\ veronica.delgado@espoch.edu.ec
}

\begin{abstract}
Catherine Andrade
School of Public Health, Escuela

Superior Politécnica de Chimborazo,

ESPOCH, Riobamba, Ecuador

catherine.andrade@espoch.edu.ec
\end{abstract}

\begin{abstract}
Previous research has explored the potential use of digital health to support maternal health in the Global South highlighting the importance of understanding the socio-cultural context to inform system design. However, the experiences of indigenous women managing pregnancy complications in Latin America remain underexplored in HCI. We present a qualitative study with 25 indigenous pregnant women in an Ecuadorian rural community looking at their experiences during complications, their antenatal care visits and their access and use of technologies. Our findings highlight key barriers that hinder the use of antenatal care services and influence women's experiences managing complications. Based on the findings, we present opportunities for digital health centered on indigenous women to enhance antenatal care in rural Ecuador.
\end{abstract}

\section{CCS CONCEPTS}

- Human-centered computing $\rightarrow$ Human computer interaction (HCI); Empirical studies in HCI.

\section{KEYWORDS}

Indigenous Women, Pregnancy Complications, Antenatal Care, Maternal Health, Digital Health, Kichwas

\footnotetext{
Permission to make digital or hard copies of all or part of this work for personal or classroom use is granted without fee provided that copies are not made or distributed for profit or commercial advantage and that copies bear this notice and the full citation on the first page. Copyrights for components of this work owned by others than ACM must be honored. Abstracting with credit is permitted. To copy otherwise, or republish, to post on servers or to redistribute to lists, requires prior specific permission and/or a fee. Request permissions from permissions@acm.org.

NordiCHI '20, October 25-29, 2020, Tallinn, Estonia

(c) 2020 Association for Computing Machinery.

ACM ISBN 978-1-4503-7579-5/20/10 . \$ \$15.00

https://doi.org/10.1145/3419249.3420141
}

\section{ACM Reference Format:}

Nervo Verdezoto, Francisca Carpio-Arias, Valeria Carpio-Arias, Nicola Mackintosh, Parisa Eslambolchilar, Verónica Delgado, Catherine Andrade, and Galo Vásconez. 2020. Indigenous Women Managing Pregnancy Complications in Rural Ecuador: Barriers and Opportunities to Enhance Antenatal Care. In Proceedings of the 11th Nordic Conference on HumanComputer Interaction: Shaping Experiences, Shaping Society (NordiCHI '20), October 25-29, 2020, Tallinn, Estonia. ACM, New York, NY, USA, 9 pages. https://doi.org/10.1145/3419249.3420141

\section{INTRODUCTION}

Maternal health is a global public health concern specially impacting low and low-to middle (LMIC) income countries [75]. Women who are illiterate and from low socio-economic status from rural and urban areas are amongst those who have lower access and uptake of antenatal care services [4, 33, 49, 67, 90, 132]. In particular, indigenous women are at risk of poor maternal and perinatal health outcomes as they suffer greater social, economic, and emotional vulnerability with extreme levels of health inequalities [2, 3, 129, 155]. Latin America (LATAM) is not an exception, extreme poverty, malnutrition, ethnic and linguistic differences, poor access to basic resources, education and health services $[6,15,27,79,106]$ do not only expose indigenous women to discrimination but also put them at risk of serious pregnancy complications $[6,9,17,29,109]$.

In this paper, we report a qualitative study with 25 indigenous pregnant women experiencing complications to uncover their care needs, experiences and challenges interacting with antenatal services and their access and use of technologies to inform the design of digital health tools to support antenatal care in rural Ecuador. 


\section{BACKGROUND}

\subsection{Maternal Health and Pregnancy Complications in Ecuador}

In Ecuador, a small multiethnic and multicultural country [38], women are increasingly at risk of experiencing the double burden of malnutrition characterized by the coexistence of under nutrition alongside obesity and overweight [41]. Pregnancy complications such as obstetric hemorrhage, gestational diabetes and pregnancyinduced hypertensive disorders (e.g., pre-eclampsia, eclampsia) $[55,94,105,128]$ are major contributors to poor maternal outcomes. Women from low-income, rural and indigenous communities have limited access to healthcare services [81] and are at high risk of experiencing pregnancy complications [18, 78, 116, 151]. For example, severe cases of hypertensive disorders have shown high rates of poor perinatal outcomes, an increase of caesarean sections and admissions to the intensive care unit $[116,151]$. Although the government has recognized the need to improve maternal health and reduce health inequalities through nutritional programs [120] and the last public health reform [46] promoting intercultural approaches $[78,148]$, these have not achieved substantial changes [126]. The maternal mortality rate has only decreased from 74 in 2005 to 64 per 1000000 live births in 2015 [153] and it is particularly high among indigenous women reaching over 100 per 1000000 live births in some provinces [105]. Major risk factors include maternal age, lack of awareness of warning signs and family support, and ethnic discrimination $[18,45,112,151]$.

\subsection{Digital Health in the Ecuadorian Context}

The use of information and communication technologies, digital health [154], is creating opportunities in Ecuador to support care practices in clinical and non-clinical settings [21, 24, 80, 125]. In clinical settings, digital health is facilitating the monitoring of vital signs [40], digitalization of medical records [56], communication and interaction between clinicians and with patients (e.g., WhatsApp) [22, 25], localization of medical areas and doctor's offices [143], and medical training and tele-consultations [147]. In nonclinical settings, mobile phones, apps, SMS, e-mail, online resources and social media (e.g., WhatsApp, YouTube, Facebook) are facilitating care after hospitalization [88] and self-care management of a variety of chronic conditions such as diabetes [92], hypertension [24], chronic kidney disease [21], asthma [23], and cancer [108] by receiving, looking and sharing information between patients and health staff. However, there is limited research exploring digital maternal health [87] and in particular among indigenous communities.

\subsection{Digital Maternal Health in the Global South}

Digital health is supporting women and healthcare staff in LMICs to enhance maternal health [62]. Digital health has increased access to information and services through videos and text messages, promoting health education and enabling women to share experiences, receive reminders and support [12, 28, 68, 69, 133]. For health staff, it is enabling remote monitoring of pregnancies, providing training support, sharing knowledge and patient information [119, 121, 144]. Most digital health initiatives focus on helping community health workers to gather accurate data during home visits, enhance screening and information-seeking practices, visualization of tasks and facilitate communication with women [34, 35, 76, 104, 145]. While the digital transformation in maternal health is opening up opportunities for HCI research for development (HCI4D) in South Africa [28, 50, 100, 133], Kenya [113, 114], Pakistan [12, 99, 127], India [35, 64, 72, 73], Bangladesh [138], Lebanon [140, 141], Uganda and Tanzania [68], there is limited research looking at women's experiences during pregnancy complications [12] and among indigenous communities $[8,57]$ and Latin America as a region remains unexplored for HCI4D research in healthcare $[19,135]$.

\subsection{Socio-cultural and Infrastructural Challenges in the Global South}

HCI4D research highlights the importance of understanding the sociocultural practices of the local context to inform the design of digital health technologies for the global south [36, 63, 111]. These challenges include existing household and community power dynamics, communication, environmental and infrastructural barriers, disconnected knowledges, beliefs, conflicts and distrust between multiple stakeholders [61, 91, 99, 111, 121, 138, 140]. Particular attention should be given to women's perceptions and relationships with the healthcare system to improve antenatal care [1, 10, 140, 141]. In Ecuador, social, ethnic, economic and regional inequalities [81] and the lack of human and physical healthcare infrastructure and access to Internet in rural communities [19] are impacting indigenous women's health and the healthcare infrastructure [7, 42, 78, 124]. There is a need to understand women's needs, contexts and lived experiences, and the sociocultural and infrastructural barriers that influence digital maternal health [64] especially in rural [111, 121] and indigenous communities and the potential role of ICTs in indigenous health $[14,57,82,150]$.

\section{RESEARCH SETTING AND METHODS}

We started a project to understand the sociocultural, and infrastructural challenges faced by indigenous women with pregnancy complications and how these influence the use of antenatal care services in rural Ecuador. While the project includes focus groups with pregnant women and interviews with healthcare staff, in this paper we only present the preliminary results from focus groups. The project team include a multidisciplinary group of researchers with background in public health, nutrition, human-computer interaction, social sciences and communication. Ecuador has a population around 16 million people $[5,37]$ and $7 \%$ of the Ecuadorian population identified themselves as indigenous [38]. 78.5\% of indigenous people are located in rural areas of the Andean Highlands that are characterized by a difficult terrain with poor roads and steep geography [139] and are often bilingual (Spanish and Kichwa) [26, 71, 77]. The health sub-center where the study took place provides outpatient services including family general medicine and obstetrics and makes referrals and counter-referrals of patients and blood tests. It is located in Colta, a small town on the northwestern part of the Chimborazo province in the Highlands, a province with one of the highest maternal mortality rates [105]. Colta has ten subcenters and one public basic hospital (Publio Escobar). The last census in Colta shows that $94.9 \%$ of the population live in rural areas [130] and 
93.27\% of the population live in poor socioeconomical conditions [30]. $87.38 \%$ of the population are indigenous [30]. We recruited and identified participants with the help of the "family" doctor who did home visits. We invited women older than 18 years with non-severe pregnancy complications that attended the antenatal consultations at the subcenter and who spoke both Spanish and Kichwa. Women with severe complications, adolescents or those attending the emergency area were excluded. Upon the doctor's recommendation, we did not compensate participants as it was considered inappropriate [74]. Participants signed or placed their fingerprint on the informed consent and a protocol was prepared in case of any discomfort during the study. The research was granted permission by community leaders of Colta and approval by Cardiff University Ethics Committee.

\subsection{Focus Groups and Data Analysis}

We conducted three focus group discussions at the sub-center in a private room, with a calm environment, accessible to the participants to encourage attendance [44]. Focus groups are usable for generating rich understandings of participants' experiences and beliefs [95], "well suited for problems in health research" [96], yielding "deeper insights" [142], and successfully applied with groups between 3 and 14 participants [44]. In particular, focus groups are suitable for exploring sensitive topics [48] especially around women's health relying on the "collective sense of women's solidarity" [152] and with pre-existing group interactions [44]. We chose to use focus groups considering the familiarity between participants and their strong sense of community and the family doctor and local researchers' experience working with these communities and prior work using focus groups with Kichwas communities [20]. This method would enable indigenous women to feel more comfortable sharing experiences in a group setting bringing upfront the collective views of the women putting them in control of the group interaction [152]. Focus groups took place in January and February 2020 and lasted approximately 60-90 minutes. Discussions centered on women's attitudes, challenges and experiences with complications with a focus on antenatal consultations, quality of care, symptoms, clarity of health advice, use of technology and general aspects to describe the participants. Open-ended questions were used to encourage participants to talk freely and to ask questions at any time and no personal information was collected (e.g., address). Participants had the opportunity to comment after the sessions if they did not feel like talking about a particular issue. The researcher acted as a moderator [44] and was female to align with the sociocultural norms in Kichwas communities [20]. Based on previous research with these communities [20], the moderation was shared between the female researcher (a trained Spanish-speaking notetaker) and a bilingual speaker (Spanish/Kichwa) per focus group (a nurse assistant, a research assistant, and a pregnant woman) who was there to assist in the event that participants preferred to express themselves in Kichwa rather than Spanish (about 50\%). Notes were taken and $90 \%$ of discussions were audio recorded and transcribed in Spanish, removing instances to personal data. For the analysis, a transcription of the recordings was made first by the researcher and assisted by the research assistant who speaks Kichwa to translate terms, words or expressions into Spanish when needed and complemented with notes. A thematic analysis [16] was performed in Spanish using open coding and constant comparison, observing the particularities of the transcripts before grouping the codes into themes. Two members of the research team reviewed the transcripts and created or discussed emerging themes looking for saturation.

\section{FINDINGS}

Three focus groups were conducted with ten, thirteen and twelve women respectively. Participants' age ranged from 19 to 43 years (average age 27.34) and they were between 7-13 weeks of pregnancy (10 weeks average) at the time of the study. All participants self-identified themselves as part of the Kichwa ethnic group. Seven participants were single, 12 married, three divorced and three were living with a partner. The majority of the participants (21) had agriculture as their main occupation, two were primary school teachers, and two identified as carers of the children at home. Seven participants were in their first pregnancy and 18 were multiparous mothers. Pregnancy complications included preeclampsia (7), gestational diabetes (8), vaginal bleeding (6), placental complications (3), and other (1). Two participants commented after a session.

\subsection{Barriers to Antenatal Care}

4.1.1 Unknown terminology used during consultation, referral process and around the subcenter. Aligned with previous research [63], a major barrier reported was the unknown medical terminology used by the healthcare staff during the consultation. As a consequence, many participants left the consultation without fully understanding the treatment plan. A participant stated, "Doctors do not speak Kichwa, and so there are many things I do not understand...”. Kichwa is predominately an oral language and one of the limitations is the lack of a written alphabet [26], making it difficult for non-indigenous people (i.e., doctors) to speak Kichwa where no direct translation exists for medical terms. Many participants reported that the information provided in connection to the referral system was not clear, "I was referred to a big hospital in Riobamba, because I got high blood pressure, but they gave me a paper and I did not know what to do with it". The unfamiliar medical terms made it difficult for women to understand referrals and get timely access to care services. Although participants valued signs (toilets, pharmacy, exit) in Kichwa at the subcenter, all information boards displayed health messages (e.g., HIV and pregnancy) with complex terms in Spanish.

4.1.2 Long waiting times for consultation and missing appointments. Similar to non-indigenous patients in resource constrained settings [107], participants stressed that long waiting times influenced their use of antenatal care services as it was difficult for them to wait while they had other responsibilities and occupations. A participant commented "We have to wait a lot of time and we have so many things to do". Most participants were in charge of growing food crops and feeding and watering animals, in particular "cuyes [guinea pigs]". Apart from farming work, housework and childcare, women sold their products and animals on Thursday at the town's market. Participants mentioned missing antenatal appointments at the subcenter or hospital as these were difficult to integrate into everyday work and life. 
4.1.3 Affective dimensions of the healthcare settings. Feelings of embarrassment and shame can take place in connection to medical examinations and can be a reason for not seeking health and is influenced by the sociocultural contexts $[101,149]$. In our study, many indigenous women felt nervous discussing intimate problems, others felt very uncomfortable when showing their private parts. A participant commented "I feel embarrassed when showing my body or intimate parts to strangers". Sociocultural norms in relation to nudity can pose stressful feelings of embarrassment over women. Some participants were concerned about being perceived as "stupid" by health staff when asking questions. A participant expressed "if I do not understand something, I feel embarrassed to ask again". At the city hospital, participants also felt ashamed for asking questions when not knowing where to go. Many participants feared negative reactions from doctors or were concerned about what doctors thought about them.

4.1.4 Delayed use of antenatal care services vs home-based remedies. Aligned to [99], women were unaware of warning signs during complications. Many participants commented that they did not often seek help for their health or use the antenatal care services regardless of the number of pregnancies, failing to recognize warning signs like pain. A participant stated, "when I feel pain, I prepare an 'agüita' [similar to an herbal tea] or take a pill, and do not go to the health center". Home-based remedies and self-medication were often practiced following the advice of female relatives (e.g., mothers) or friends.

4.1.5 Traditional gender structures in indigenous communities. Similar to other cultures with patriarchal systems [93, 98, 99], gender roles in the Ecuadorian Andean communities are also prominent [20]. Participants commented how they followed their husbands' decisions who often discouraged them from using antenatal care services. A married woman commented " $m y$ husband does not like me to come often". Participants in general were positive about the home visits: "It is good that they [doctors] are visiting us at home, I did not know that I got a control check and the doctor arrived to explain $m e$ ". However, other participants mentioned that their husbands did not like the home visits in the case of male doctors, "If a female doctor comes there is no problem, but if a male doctor comes, my husband gets mad". Gendered and social expectations of women's behaviors within the indigenous male-female relations influenced women's agency and help-seeking practices contributing to their marginalization.

4.1.6 Intentional non-adherence to medications. Similar to previous studies with non-indigenous people [31,131], participants reported intentional non-adherence when deciding not to follow the medication regimen. A woman commented that she skipped her medication due to a bad taste "The other day I was having pain, the doctor prescribed me some large white pills, but they were bitter, and I did not take them". Other participants mentioned that the family doctor provided iron supplementation, but they did not take them due to stomach pain. The lack of medications at the subcenter and women's low socio-economic status influenced antenatal care as women had difficulties purchasing medications, "we do not have money to buy the pills that are not available [at subcenter]".
4.1.7 Poor road accessibility and lack of public transportation. Some participants reported that they felt that the long distances between their home and the health subcenter made it difficult to attend antenatal consultations. A woman stated, "I live far away, and buses are not frequently coming". The high altitude, steep topography of the mountains and poor road accessibly in rural communities [139] in the Andean region required women to walk long distances to the nearest highway in a steep terrain and wait for hours for public transport [47] missing appointments at the subcenter or hospitals.

\subsection{Access and Use of Technology}

Twenty-two participants reported using social networks (e.g., Facebook, WhatsApp) in Spanish because their children and family used them and it was cheap as "sometimes we can recharge with $\$ 3$ dollars and we can use WhatsApp all month". Five participants reported using the radio and few of them played videos in YouTube in Spanish assisted by their children. Two participants had computers at home, but noted they did not know how use them. Eighteen participants had used computers during their learning at school and had received a computer's introductory course years ago at the community "Infocentro[telecenter]", but still found them difficult to use. Participants could get access to computers and Internet at the "Infocentro" and free Wi-Fi near the administration office ("Junta Cantonal"). The government implemented a network of Infocentros to contribute to the development of rural communities providing access to computers, Internet, and other e-services. Colta has one Infocentro with 6 workstations [60]. About the potential use of ICTs for antenatal care, participants commented that a simple application with short health messages could be helpful.

\section{DISCUSSION AND CONCLUSION}

Our study highlights key challenges influencing not only the use of antenatal care services but also women's experiences with pregnancy complications (gestational diabetes, preeclampsia, etc.) in a rural LATAM community. Major barriers relate to the healthcare settings (consultation, complex medical terminology, long waiting times) and sociocultural (gender roles, norms and traditions), behavioral (intentional nonadherence to medication), emotional (feelings of embarrassment), and environmental (steepness of the terrain, poor road accessibility, low-frequency of public transport) factors that influence the health-seeking practices of indigenous women resulting in missing appointments and delayed access to care, exacerbating the existing clinical risks of pregnancy complications. Reflecting on these challenges and on previous HCI4D research understanding rural women's needs, our study extends existing research on digital maternal health $[72,99,111,138,141,144]$, indigenous communities $[8,57]$ and postcolonial computing [136] as the health needs and experiences in LATAM contexts still remain poorly understood in HCI4D and health research [20, 135].

In the context of Kichwas communities, similar to other resourceconstrained settings $[72,113]$, our study revealed the potential use of social and mobile technologies to support health-seeking practices in contrast to computers that seem difficult to use and not available at home. Although participants favored the use of simple interventions, these might not be enough to support the overall pregnancy care experience. Simple interventions such as apps with 
translations of medical terminology [134], reminders, automatic voice calls, SMS and persuasive messages [12, 59, 72, 113], could have limited impact in these communities. For example, the complex medical terminology was difficult to understand in textual and verbal form in Spanish with little translation available in Kichwa due to its writing limitations. Furthermore mobile technology can offer opportunities to enhance doctor's home visits [34, 35, 121] and the medication informational order [31, 32] (e.g., what, when, how and why to take a medication) at home, and can facilitate the self-management of gestational diabetes to control weight gain [53] Introducing self-monitoring devices both at the rural subcenters and at home can facilitate the early detection and management of hypertensive disorders during pregnancy [102, 103]. However, digital health should go beyond supporting medical care and oneway strategies [146] and focus on understanding and supporting indigenous women's wellbeing $[51,89]$ accounting for the ethnic diversity and sociocultural and affective dimensions of health beyond language.

One way to achieve this is to take advantage of the indigenous sense of community through the use of community-based participatory approaches $[14,43,65,91]$ to help women voice their concerns, receive support, and help balance $[137,138,141]$ the unequal gender relations and hierarchies within households and healthcare settings. Thus, future research should explore how to enable indigenous women to construct the experiential knowledge by promoting community participation through for example community radio shows [97, 140] or low-cost video projections [73] in Spanish and/or Kichwa. The combination of oral, visual $[63,64]$, art-based [85] and traditional dance [66] can help explain the risk of complications and help women distinguish between warning signs and normal changes of pregnancy and encourage them to speak up and seek help. Considering the lack of connectivity in the Highlands, this will require the establishment of community wireless networks $[118,122,123]$ to enable interaction and content sharing within the community [117]. Collective interventions should promote empathic care [70] and social support [115] encouraging participation of partners [114], caregivers, and the community, helping preserve $[58,110]$ the indigenous knowledge, traditions, and language that are unique to Kichwa communities. Last, our study highlights how women perceived social risks (cultural, emotional) [11] in relation to healthcare staff and settings having fears of judgement and embarrassment. Future research should look at how spaces and places influence indigenous health and the affective atmospheres of clinical encounters [83].

Our exploratory work has limitations. First, even though our inclusion criteria did not target a particular period of pregnancy our participants turned out to be within the first 7-13 weeks of pregnancy. The collective opinions, concerns and experiences of this group, even if they shared experiences from previous pregnancies (only 7 participants were in their first pregnancy), might not provide an overall picture of the complications in this geographic area nor account for all experiences throughout the pregnancy journey and maternal age (e.g., adolescents). Second, although all women identified themselves as bilingual and knew each other and confirmed they were comfortable during the sessions, a few of them had problems articulating their opinions. To deal with this, future work should consider conducting studies in Kichwa to increase participation as well as the use of visual methods [86] to support the discussions and help women externalize emotions and feelings when they are shy or when literacy can be an issue, increasing sensibility towards women's lived experiences [85]. Our next step includes analyzing the staff interviews looking at similarities and tensions between women's and staff perspectives. We are also looking for funding to follow up on this work combining socio-material approaches [84] and practice theory $[13,39,52]$ with community-based participatory approaches $[14,43,65,91]$ to further understand indigenous women's needs and experiences and involve them in the design of digital health interventions [54]. Our findings are far from complete and we encourage the HCI community to further investigate indigenous women's reproductive health needs in LATAM contexts to inform the design of culturally appropriate digital health tools to enhance women's health in the Global South.

\section{ACKNOWLEDGMENTS}

The authors would like to thank all the participants for their support and openness while conducting the study. The first author would like to acknowledge the Centre for Artificial Intelligence, Robotics and Human-Machine Systems (IROHMS) operation C82092, part-funded by the European Regional Development Fund (ERDF) through the Welsh Government.

\section{REFERENCES}

[1] Abrahams, N., Jewkes, R. and Mvo, Z. 2001. Health care-seeking practices of pregnant women and the role of the midwife in Cape Town, South Africa. The Journal of Midwifery \& Women's Health. 46, 4 (2001), 240-247.

[2] Agrawal, P.K. and Agrawal, S. 2010. To what extent are the indigenous women of Jharkhand, India living in disadvantageous conditions: findings from India's National Family Health Survey 1. Asian Ethnicity. 11, 1 (2010), 61-80.

[3] Akter, S., Rich, J.L., Davies, K. and Inder, K.J. 2019. Access to maternal healthcare services among Indigenous women in the Chittagong Hill Tracts, Bangladesh: A cross-sectional study. BMJ open. 9, 10 (2019).

[4] Alcock, G., Das, S., More, N.S., Hate, K., More, S., Pantvaidya, S., Osrin, D. and Houweling, T.A. 2015. Examining inequalities in uptake of maternal health care and choice of provider in underserved urban areas of Mumbai, India: a mixed methods study. BMC pregnancy and childbirth. 15, 1 (2015), 231.

[5] Aldulaimi, S. and Mora, F.E. 2017. A primary care system to improve health care efficiency: lessons from Ecuador. The Journal of the American Board of Family Medicine. 30, 3 (2017), 380-383.

[6] Armenta Paulino, N., Sandín Vázquez, M. and Bolúmar, F. 2019. Indigenous language and inequitable maternal health care, Guatemala, Mexico, Peru and the Plurinational State of Bolivia. Bulletin of the World Health Organization. 97, 1 (2019).

[7] Arteaga, E.L., San Sebastián, M. and Amores, A. 2012. Construcción participativa de indicadores de la implementación del modelo de salud intercultural del cantón Loreto, Ecuador. Saude em debate. 36, (2012), 402-413.

[8] Ashraf, M.M., Grunfeld, H. and Quazi, A. 2015. Impact of ICT usage on indigenous peoples' quality of life: Evidence from an Asian developing country. Australasian Journal of Information Systems. 19, (2015).

[9] Austad, K., Juarez, M., Shryer, H., Moratoya, C. and Rohloff, P. 2020. Obstetric care navigation: results of a quality improvement project to provide accompaniment to women for facility-based maternity care in rural Guatemala. BMJ quality \& safety. 29, 2 (2020), 169-178.

[10] Bagalkot, N., Verdezoto, N., Lewis, M., Griffiths, P., Harrington, D., Mackintosh, N. and Noronha, J.A. 2018. Towards Enhancing Everyday Pregnancy Care: Reflections from Community Stakeholders in South India. Proceedings of the 9th Indian Conference on Human Computer Interaction (2018), 71-74.

[11] Barclay, L., Kornelsen, J., Longman, J., Robin, S., Kruske, S., Kildea, S., Pilcher, J., Martin, T., Grzybowski, S., Donoghue, D., Rolfe, M. and Morgan, G. 2016. Reconceptualising risk: Perceptions of risk in rural and remote maternity service planning. Reconceptualising Risk in Childbirth. 38, (Jul. 2016), 63-70. DOI:https: //doi.org/10.1016/j.midw.2016.04.007.

[12] Batool, A., Razaq, S., Javaid, M., Fatima, B. and Toyama, K. 2017. Maternal Complications: Nuances in Mobile Interventions for Maternal Health in Urban 
Pakistan. Proceedings of the Ninth International Conference on Information and Communication Technologies and Development (2017), 3.

[13] Blue, S., Shove, E., Carmona, C. and Kelly, M.P. 2016. Theories of practice and public health: understanding (un) healthy practices. Critical Public Health. 26, 1 (2016), 36-50.

[14] Bodeker, G. and Kariippanon, K. 2020. Traditional Medicine and Indigenous Health in Indigenous Hands. Oxford Research Encyclopedia of Global Public Health.

[15] Borges, M.C., Buffarini, R., Santos, R.V., Cardoso, A.M., Welch, J.R., Garnelo, L., Coimbra, C.E.A. and Horta, B.L. 2016. Anemia among indigenous women in Brazil: findings from the First National Survey of Indigenous People's Health and Nutrition. BMC Women's Health. 16, 1 (Feb. 2016), 7. DOI:https://doi.org/ 10.1186/s12905-016-0287-5.

[16] Braun, V. and Clarke, V. 2006. Using thematic analysis in psychology. Qualitative research in psychology. 3, 2 (2006), 77-101.

[17] Bryson, C.L., Ioannou, G.N., Rulyak, S.J. and Critchlow, C. 2003. Association between gestational diabetes and pregnancy-induced hypertension. American journal of epidemiology. 158, 12 (2003), 1148-1153.

[18] Bustamante, G., Mantilla, B., Cabrera-Barona, P., Barragán, E., Soria, S., Quizhpe, E., Aguilar, A.J., Trujillo, M.H., Wang, E. and Grunauer, M. 2019. Awareness of obstetric warning signs in Ecuador: a cross-sectional study. Public health. 172 (2019), 52-60.

[19] Carlo, L., Carpio, V., Verdezoto, N., Eslambolchilar, P., Cruz, E., Malo, F. and Espinosa, D. 2020. Healthcare Infrastructures in Ecuador: Challenges, Reflections and Opportunities for Digital Health. Proceedings of the 2020 International Conference on Information and Communication Technologies and Development (2020), 1-6.

[20] Chee, V.A., Teran, E., Hernandez, I., Wright, L., Izurieta, R., Reina-Ortiz M., Flores, M., Bejarano, S., Dào, L.U. and Baldwin, J. 2019. 'Desculturización,'urbanization, and nutrition transition among urban Kichwas Indigenous communities residing in the Andes highlands of Ecuador. Public Health. 176, (2019), 21-28.

[21] Cherrez-Ojeda, I., Felix, M., Mata, V.L, Vanegas, E., Gavilanes, A.W., Chedraui, P., Simancas-Racines, D., Calderon, J.C., Ortiz, F. and Blum, G. 2018. Preferences of ICT among Patients with Chronic Kidney Disease Undergoing Hemodialysis An Ecuadorian Cross-Sectional Study. Healthcare informatics research. 24, 4 (2018), 292-299.

[22] Chérrez-Ojeda, I., Felix, M., Mata, V.L., Vanegas, E., Simancas-Racines, D. Aguilar, M., Gavilanes, A.W., Chedraui, P. and Vera, C. 2020. Use and perceptions of information and communication technologies among Ecuadorian nurses: a cross-sectional study. The Open Nursing Journal. 14, 1 (2020).

[23] Chérrez-Ojeda, I., Plaza, K., Cano, J.A., Carlos Calderón, J., Chérrez, A., Baptist, A., Calero, E., Hoyos, R., Beltrán, P. and Cruz, V. 2017. Does Ecuadorians with asthma has preferences in the use of information and communication technologies? Pilot study. Revista Alergia de Mexico. 64, 4 (2017).

[24] Chérrez-Ojeda, I., Vanegas, E., Felix, M., Mata, V.L., Gavilanes, A.W. and Chedraui, P. 2019. Use and preferences of information and communication technologies in patients with hypertension: a cross-sectional study in Ecuador Journal of multidisciplinary healthcare. 12, (2019), 583

[25] Chérrez-Ojeda, I., Vera, C., Vanegas, E., Gallardo, J.C., Felix, M., EspinozaFuentes, F., Chedraui, P., Gavilanes, A.W. and Mata, V.L. 2020. The use of information and communication technologies in Latin American dentists: a cross-sectional study from Ecuador. BMC Oral Health. 20, (2020), 1-9.

[26] Chisaguano, S. 2006. La población indígena del Ecuador. Instituto Nacional de Estadísticas y Censos (INEC).

[27] Chomat, A.M., Solomons, N.W., Montenegro, G., Crowley, C. and Bermudez, O.I. 2014. Maternal health and health-seeking behaviors among indigenous Mam mothers from Quetzaltenango, Guatemala. Revista Panamericana de Salud Pública. 35, (2014), 113-120.

[28] Coleman, J. 2018. Sawubona MAMA: Using mHealth to improve maternal, neonatal and child health outcomes in South Africa. (2018).

[29] Conde-Agudelo, A., Belizán, J.M. and Lammers, C. 2005. Maternal-perinatal morbidity and mortality associated with adolescent pregnancy in Latin America: Cross-sectional study. American journal of obstetrics and gynecology. 192, 2 (2005), 342-349.

[30] Contrato Social Ecuador 2016. Diálogo cantonal sobre educación: COLTA Provincia de Chimborazo. Contrato Social por la Educación Ecuador.

[31] Dalgaard, L.G., Grönvall, E. and Verdezoto, N. 2013. Accounting for medication particularities: designing for everyday medication management. Pervasive Computing Technologies for Healthcare (PervasiveHealth), 2013 7th International Conference on (2013), 137-144.

[32] Dalgaard, L.G., Grönvall, E. and Verdezoto, N. 2013. MediFrame: a tablet application to plan, inform, remind and sustain older adults' medication intake. 2013 IEEE International Conference on Healthcare Informatics (2013), 36-45.

[33] De Groot, A., Van de Munt, L., Boateng, D., Savitri, A.I., Antwi, E., Bolten, N., Klipstein-Grobusch, K., Uiterwaal, C.S.P.M. and Browne, J.L. 2019. Equity in maternal health outcomes in a middle-income urban setting: a cohort study. Reproductive Health. 16, 1 (Jun. 2019), 84. DOI:https://doi.org/10.1186/s12978-
019-0736-3.

[34] DeRenzi, B., Borriello, G., Jackson, J., Kumar, V.S., Parikh, T.S., Virk, P. and Lesh, N. 2011. Mobile phone tools for field-based health care workers in low-income countries. Mount Sinai Journal of Medicine: A Journal of Translational and Personalized Medicine. 78, 3 (2011), 406-418.

[35] DeRenzi, B., Dell, N., Wacksman, J., Lee, S. and Lesh, N. 2017. Supporting community health workers in India through voice-and web-based feedback. Proceedings of the 2017 CHI Conference on Human Factors in Computing Systems (2017), $2770-2781$

[36] Donaldson, K. 2008. Why to be wary of "Design for Developing Countries." Ambidextrous 9 (2008), 35. 37, (2008).

[37] Ecuador Country Profile: 2018. https://www.who.int/countries/ecu/en/. Accessed: 2020-03-05.

[38] Ecuador Ethnic groups: 2019. https://www.indexmundi.com/ecuador/ethnic groups.html. Accessed: 2010-03-05.

[39] Entwistle, J.M., Rasmussen, M.K., Verdezoto, N., Brewer, R.S. and Andersen, M.S. 2015. Beyond the Individual: The Contextual Wheel of Practice As a Research Framework for Sustainable HCI. Proceedings of the 33rd Annual ACM Conference on Human Factors in Computing Systems (New York, NY, USA, 2015), $1125-1134$.

[40] Espinoza, J., Chandy, D., Ochoa, S., Jiménez, J., Huerta, M., Soto, A., Sagbay, G. and Avila, R. 2016. Design of telemedicine management system in ecuador. 2016 IEEE Ecuador Technical Chapters Meeting (ETCM) (2016), 1-6.

[41] Freire, W.B., Waters, W.F., Rivas-Mariño, G. and Belmont, P. 2018. The double burden of chronic malnutrition and overweight and obesity in Ecuadorian mothers and children, 1986-2012. Nutrition and health. 24, 3 (2018), 163-170.

[42] Gallegos, C.A., Waters, W.F. and Kuhlmann, A.S. 2017. Discourse versus practice: are traditional practices and beliefs in pregnancy and childbirth included or excluded in the Ecuadorian health care system? International health. 9, 2 (2017), $105-111$.

[43] Gentry, J. and Metz, B. 2017. Adjusting Photovoice for Marginalized Indigenous Women: Eliciting Ch'orti'Maya Women's Perspectives on Health in Guatemala. Human Organization. 76, 3 (2017), 251-263.

[44] Gill, P., Stewart, K., Treasure, E. and Chadwick, B. 2008. Methods of data collection in qualitative research: interviews and focus groups. British dental journal. 204, 6 (2008), 291-295.

[45] González-Andrade, F. and López-Pulles, R. 2010. Congenital malformations in Ecuadorian children: urgent need to create a National Registry of Birth Defects. The application of clinical genetics. 3, (2010), 29.

[46] Granda, M.L. and Jimenez, W.G. 2019. The evolution of socioeconomic health inequalities in Ecuador during a public health system reform (2006-2014). International Journal for Equity in Health. 18, 1 (Feb. 2019), 31. DOI:https: //doi.org/10.1186/s12939-018-0905-y.

[47] Guambi, M. 2010. Fortalecimiento de la gestión técnica administrativa de la consulta externa del Hospital Publio Escobar de Colta. Universidad Técnica Particular de Loja.

[48] Guest, G., Namey, E., Taylor, J., Eley, N. and McKenna, K. 2017. Comparing focus groups and individual interviews: findings from a randomized study. International Journal of Social Research Methodology. 20, 6 (2017), 693-708.

[49] Hamal, M., Dieleman, M., De Brouwere, V. and de Cock Buning, T. 2020. Social determinants of maternal health: a scoping review of factors influencing maternal mortality and maternal health service use in India. Public Health Reviews. 41, 1 (Jun. 2020), 13. DOI:https://doi.org/10.1186/s40985-020-00125-6.

[50] van Heerden, A., Norris, S., Tollman, S., Richter, L. and Rotheram-Borus, J.M. 2013. Collecting Maternal Health Information From HIV-Positive Pregnant Women Using Mobile Phone-Assisted Face-to-Face Interviews in Southern Africa. J Med Internet Res. 15, 6 (Jun. 2013), e116. DOI:https://doi.org/10.2196/ jmir.2207.

[51] Hensel, J.M., Ellard, K., Koltek, M., Wilson, G. and Sareen, J. 2019. Digital health solutions for indigenous mental well-being. Current psychiatry reports. 21, 8 (2019), 68.

[52] Henwood, F. and Marent, B. 2019. Understanding digital health: Productive tensions at the intersection of sociology of health and science and technology studies. Sociology of health \& illness. 41, (2019), 1-15.

[53] Hirst, J.E., Mackillop, L., Loerup, L., Kevat, D.A., Bartlett, K., Gibson, O., Kenworthy, Y., Levy, J.C., Tarassenko, L. and Farmer, A. 2014. Acceptability and user satisfaction of a smartphone-based, interactive blood glucose management system in women with gestational diabetes mellitus. Journal of diabetes science and technology. 9, 1 (2014), 111-115.

[54] Holeman, I. and Kane, D. 2019. Human-centered design for global health equity. Information Technology for Development. (2019), 1-29.

[55] Holguín, A., Damaris, N. and Karanovic Vélez, N.N. 2019. Prevalencia del síndrome de HELLP en gestantes con preeclampsia y eclampsia del servicio de Ginecología-Obstetricia del Hospital General Guasmo Sur período enero a junio del 2017. (2019)

[56] Holguin, A. and Guarda, T. 2018. Electronic health and its advances in Ecuador. 2018 13th Iberian Conference on Information Systems and Technologies (CISTI) (2018), 1-3. 
[57] Hoque, M.R. and Ashraf, M.M. 2015. An ICT4D project for promoting health awareness programmes in indigenous community. Proceedings of the Seventh International Conference on Information and Communication Technologies and Development (2015), 1-4.

[58] Hunter, J. 2005. The role of information technologies in indigenous knowledge management. Australian Academic \& Research Libraries. 36, 2 (2005), 109-124.

[59] Ikwunne, T.A. and Orji, R. 2016. Personalized Persuasive Messaging System for Reducing Patient's Dissatisfaction With Prolonged Waiting Times. PPT@ PERSUASIVE (2016), 74-82.

[60] Infocentros. Conectando con mi País. Conectando con mi gente: https:// infocentros.mintel.gob.ec/. Accessed: 2020-04-01.

[61] Ismail, A., Karusala, N. and Kumar, N. 2018. Bridging Disconnected Knowledges for Community Health. Proc. ACM Hum.-Comput. Interact. 2, Article 75, (2018) 27 pages.

[62] Iyawa, G.E. and Hamunyela, S. 2019. mHealth apps and services for maternal healthcare in developing countries. 2019 IST-Africa Week Conference (ISTAfrica) (2019), 1-10.

[63] Joshi, A., Rane, M., Roy, D., Sali, S., Bharshankar, N., Kumarasamy, N., Pujari, S., Solomon, D., Sharma, H.D. and Saple, D.G. 2011. Design opportunities for supporting treatment of people living with HIV/AIDS in India. IFIP Conference on Human-Computer Interaction (2011), 315-332.

[64] Joshi, A., Roy, D., Ganju, A., Joshi, M. and Sharma, S. 2019. ICT Acceptance for Information Seeking Amongst Pre-and Postnatal Women in Urban Slums. IFIP Conference on Human-Computer Interaction (2019), 152-160.

[65] Kaholokula, J.K., Ing, C.T., Look, M.A., Delafield, R. and Sinclair, K. 2018 Culturally responsive approaches to health promotion for Native Hawaiians and Pacific Islanders. Annals of Human Biology. 45, 3 (Apr. 2018), 249-263. DOI:https://doi.org/10.1080/03014460.2018.1465593.

[66] Kaholokula, J.K., Look, M., Mabellos, T., Zhang, G., de Silva, M., Yoshimura, S. Solatorio, C., Wills, T., Seto, T.B. and Ka'imi, A.S. 2017. Cultural dance program improves hypertension management for Native Hawaiians and Pacific Islanders: A pilot randomized trial. Journal of racial and ethnic health disparities. 4, 1 (2017), 35-46.

[67] Kaku, N. and Patil, R. 2020. Dual-Malnutrition Burden in Lower Socioeconomic Status Women in Mumbai. Ecology of Food and Nutrition. (2020), 1-12.

[68] Katusiime, J. and Pinkwart, N. 2016. Supporting Maternal Health Education in Developing Countries Using Mobile Phones-Results of a Pilot Study. Proceedings of the First African Conference on Human Computer Interaction (2016), 48-57.

[69] Kazakos, K., Asthana, S., Balaam, M., Duggal, M., Holden, A., Jamir, L., Kannuri, N.K., Kumar, S., Manindla, A.R. and Manikam, S.A. 2016. A real-time ivr platform for community radio. Proceedings of the $2016 \mathrm{CHI}$ Conference on Human Factors in Computing Systems (2016), 343-354.

[70] Kendall, E. and Barnett, L. 2015. Principles for the development of Aboriginal health interventions: culturally appropriate methods through systemic empathy. Ethnicity \& Health. 20, 5 (Sep. 2015), 437-452. DOI:https://doi.org/10.1080/ 13557858.2014.921897.

[71] Knapp, G. 2020. The Changing Kichwa Language Map in Ecuador. Handbook of the Changing World Language Map. (2020), 1731-1742.

[72] Kumar, N. and Anderson, R.J. 2015. Mobile phones for maternal health in rural India. Proceedings of the 33rd Annual ACM Conference on Human Factors in Computing Systems (2015), 427-436.

[73] Kumar, N., Perrier, T., Desmond, M., Israel-Ballard, K., Kumar, V., Mahapatra, S., Mishra, A., Agarwal, S., Gandhi, R. and Lal, P. 2015. Projecting health community-led video education for maternal health. Proceedings of the Seventh International Conference on Information and Communication Technologies and Development (2015), 17.

[74] Largent, E.A. and Lynch, H.F. 2017. Paying research participants: regulatory uncertainty, conceptual confusion, and a path forward. Yale journal of health policy, law, and ethics. 17, 1 (2017), 61.

[75] Lawn, J.E. et al. 2016. Stillbirths: rates, risk factors, and acceleration towards 2030 The Lancet. 387, 10018 (Feb. 2016), 587-603. DOI:https://doi.org/10.1016/S01406736(15)00837-5.

[76] LeFevre, A.E., Dane, P., Copley, C.J., Pienaar, C., Parsons, A.N., Engelhard, M., Woods, D., Bekker, M., Benjamin, P. and Pillay, Y. 2018. Unpacking the perfor mance of a mobile health information messaging program for mothers (MomConnect) in South Africa: evidence on program reach and messaging exposure BMJ global health. 3, Suppl 2 (2018), e000583.

[77] Limerick, N. 2020. Speaking for a State: Standardized Kichwa Greetings and Conundrums of Commensuration in Intercultural Ecuador. Signs and Society. 8 2 (2020), 185-219.

[78] Llamas, A. and Mayhew, S. 2018. "Five hundred years of medicine gone to waste"? Negotiating the implementation of an intercultural health policy in the Ecuadorian Andes. BMC public health. 18, 1 (2018), 686.

[79] Loewenberg, S. 2010. Maricela Zurita Cruz: voice for Mexican Indigenous women's health. The Lancet. 375, 9727 (2010), 1685.

[80] López Pulles, I.R., Chiriboga Urquizo, M. and Carrera, A. 2017. The present situation of e-health and mHealth in Ecuador. Latin American Journal of Telehealth.
4, (2017), 261-267

[81] Lopez-Cevallos, D. and Chi, C. 2012. Inequity in health care utilization in Ecuador: an analysis of current issues and potential solutions. International journal for equity in health (2012), A6.

[82] Loudon, G., Kumar, C.S., Sreekumar, K. T. Haritha, H, and Kuruvachan, K.G. 2019. Empowering indigenous communities in India through the use of design thinking methods. ESRC/AHRC GCRF Indigenous Methods Workshop. (2019).

[83] Lupton, D. 2017. How does health feel? Towards research on the affective atmospheres of digital health. DIGITAL HEALTH. 3, (2017), 2055207617701276.

[84] Lupton, D. 2019. Toward a More-Than-Human Analysis of Digital Health: Inspirations From Feminist New Materialism. Qualitative health research. (2019), 1049732319833368.

[85] Mackintosh, N., Sandall, J., Collison, C., Carter, W. and Harris, J. 2018. Employing the arts for knowledge production and translation: Visualizing new possibilities for women speaking up about safety concerns in maternity. Health Expectations. 21, 3 (2018), 647-658.

[86] Mannay, D., Creaghan, J., Gallagher, D., Marzella, R., Mason, S., Morgan, M. and Grant, A. 2018. Negotiating closed doors and constraining deadlines: the potential of visual ethnography to effectually explore private and public spaces of motherhood and parenting. Journal of contemporary ethnography. 47, 6 (2018), 758-781.

[87] Maslowsky, J., Frost, S., Hendrick, C.E., Trujillo Cruz, F.O. and Merajver, S.D. 2016. Effects of postpartum mobile phone-based education on maternal and infant health in Ecuador. International Journal of Gynecology \& Obstetrics. 134, 1 (Jul. 2016), 93-98. DOI:https://doi.org/10.1016/j.ijgo.2015.12.008.

[88] Maslowsky, J., Valsangkar, B., Chung, J., Rasanathan, J., Cruz, F.T., Ochoa, M., Chiriboga, M., Astudillo, F., Heisler, M. and Merajver, S. 2012. Engaging patients via mobile phone technology to assist follow-up after hospitalization in Quito, Ecuador. Telemedicine and e-Health. 18, 4 (2012), 277-283.

[89] Maxwell, H. 2020. Digital health technologies, physical activity and indigenous women's wellbeing: enabling possibilities? 3rd Advancing Community Cohesion Conference (2020),

[90] Mberu, B.U., Haregu, T.N., Kyobutungi, C. and Ezeh, A.C. 2016. Health and health-related indicators in slum, rural, and urban communities: a comparative analysis. Global health action. 9, 1 (2016), 33163.

[91] Mburu, C.W., Wardle, C.-J., Joolay, Y. and Densmore, M. 2018. Co-designing with mothers and neonatal unit staff: use of technology to support mothers of preterm infants. Proceedings of the Second African Conference for Human Computer Interaction: Thriving Communities (2018), 12.

[92] Medina-Moreira, J., Lagos-Ortiz, K., Luna-Aveiga, H., Paredes, R. and ValenciaGarcía, R. 2016. Usage of diabetes self-management mobile technology: options for ecuador. International Conference on Technologies and Innovation (2016), 79-89.

[93] Moghadam, V.M. 1992. Patriarchy and the politics of gender in modernising societies: Iran, Pakistan and Afghanistan. International Sociology. 7, 1 (1992), $35-53$.

[94] Moreno-Martín, G., Martínez-Martínez, R., Moreno-Martín, M., Fernández-Nieto, M.I. and Sanabria-Negrín, J.G. 2019. Mortalidad materna en Ambato, Ecuador. 2005-2014. Revista de la Facultad de Medicina. 67, 1 (2019), 57-62.

[95] Morgan, D.L. 1997. The focus group guidebook. Sage publications.

[96] Morse, J.M. 1994. Critical issues in qualitative research methods. Sage.

[97] Mubarak, E., Shahid, T., Mustafa, M. and Naseem, M. 2020. Does Gender and Accent of Voice Matter? An Interactive Voice Response (IVR) experiment. Proceedings of the 2020 International Conference on Information and Communication Technologies and Development (2020), 1-5.

[98] Mumtaz, Z. and Salway, S. 2009. Understanding gendered influences on women's reproductive health in Pakistan: moving beyond the autonomy paradigm. Social science \& medicine. 68, 7 (2009), 1349-1356.

[99] Mustafa, M., Batool, A., Fatima, B., Nawaz, F., Toyama, K. and Raza, A.A. 2020. Patriarchy, Maternal Health and Spiritual Healing: Designing Maternal Health Interventions in Pakistan. Proceedings of the 2020 CHI Conference on Human Factors in Computing Systems. Association for Computing Machinery.

[100] Mutsai, T. and Coleman, E. 2019. Towards an Understanding of Post-Adoption Usage Behaviours in the Context of M-Health Pregnancy Support Applications. Proceedings of the South African Institute of Computer Scientists and Information Technologists 2019. 1-11.

[101] Mwini-Nyaledzigbor, P.P., Agana, A.A. and Pilkington, F.B. 2013. Lived experiences of Ghanaian women with obstetric fistula. Health care for women international. 34, 6 (2013), 440-460

[102] Nathan, H.L., Boene, H., Munguambe, K., Sevene, E., Akeju, D., Adetoro, O.O. Charanthimath, U., Bellad, M.B., De Greeff, A. and Anthony, J. 2018. The CRADLE vital signs alert: qualitative evaluation of a novel device designed for use in pregnancy by healthcare workers in low-resource settings. Reproductive health. 15, 1 (2018), 1-11.

[103] Nathan, H.L., Vousden, N., Lawley, E., de Greeff, A., Hezelgrave, N.L., Sloan, N., Tanna, N., Goudar, S.S., Gidiri, M.F. and Sandall, J. 2018. Development and evaluation of a novel Vital Signs Alert device for use in pregnancy in lowresource settings. BMJ innovations. 4, 4 (2018), 192-198. 
[104] Neupane, S., Odendaal, W., Friedman, I., Jassat, W., Schneider, H. and Doherty, T 2014. Comparing a paper based monitoring and evaluation system to a mHealth system to support the national community health worker programme, South Africa: an evaluation. BMC medical informatics and decision making. 14, 1 (2014), 69

[105] Noboa Cruz, H. 2019. Mortalidad Materna en el Ecuador: Una mirada crítica Plataforma por el Derecho a la Salud.

[106] Noreña-Herrera, C., Leyva-Flores, R., Palacio-Mejía, L.S. and Duarte-Gómez M.B. 2015. Inequidad en la utilización de servicios de salud reproductiva en Colombia en mujeres indígenas y afrodescendientes. Cadernos de Saúde Pública. $31,(2015), 2635-2648$.

[107] Oche, M.O. and Adamu, H. 2013. Determinants of patient waiting time in the general outpatient department of a tertiary health institution in north Western Nigeria. Annals of medical and health sciences research. 3, 4 (2013), 588-592.

[108] Ojeda, I.C., Vanegas, E., Torres, M., Calderón, J.C., Calero, E., Cherrez, A., Felix, M., Mata, V., Cherrez, S. and Simancas, D. 2018. Ecuadorian Cancer Patients' Preference for Information and Communication Technologies: Cross-Sectional Study. Journal of medical Internet research. 20, 2 (2018), e50.

[109] Ota, E., Ganchimeg, T., Mori, R. and Souza, J.P. 2014. Risk factors of pre eclampsia/eclampsia and its adverse outcomes in low-and middle-income countries: a WHO secondary analysis. PloS one. 9, 3 (2014), e91198.

[110] Owiny, S.A., Mehta, K. and Maretzki, A.N. 2014. The use of social media technologies to create, preserve, and disseminate indigenous knowledge and skills to communities in East Africa. International Journal of Communication. 8, (2014) 14.

[111] Parmar, V. and Keyson, D. 2008. Persuasive technology for shaping social beliefs of rural women in India: an approach based on the theory of planned behaviour International Conference on Persuasive Technology (2008), 104-115.

[112] Paz, C., Sánchez, M.E., Sarmiento, I. and Leone, P.E. 2006. Genetics and congenita malformations: interpretations, attitudes and practices in suburban communities and the shamans of Ecuador. Public Health Genomics. 9, 4 (2006), 268-273.

[113] Perrier, T., Dell, N., DeRenzi, B., Anderson, R., Kinuthia, J., Unger, J. and JohnStewart, G. 2015. Engaging pregnant women in Kenya with a hybrid computerhuman SMS communication system. Proceedings of the 33rd Annual ACM Conference on Human Factors in Computing Systems (2015), 1429-1438.

[114] Perrier, T., Harrington, E.K., Ronen, K., Matemo, D., Kinuthia, J., John-Stewart, G., Anderson, R. and Unger, J.A. 2018. Male partner engagement in family planning SMS conversations at Kenyan health clinics. Proceedings of the 1st ACM SIGCAS Conference on Computing and Sustainable Societies (2018), 3.

[115] Peyton, T. and Wisniewski, P. 2019. Improving a design space: Pregnancy as a collaborative information and social support ecology. Future of Information and Communication Conference (2019), 505-525

[116] Phoa, K.Y.N., Chedraui, P., Pérez-López, F.R., Wendte, J.F., Ghiabi, S., Vrijkotte, T and Pinto, P. 2016. Perinatal outcome in singleton pregnancies complicated with preeclampsia and eclampsia in Ecuador. Journal of Obstetrics and Gynaecology. 36, 5 (2016), 581-584.

[117] Phokeer, A., Densmore, M., Johnson, D. and Feamster, N. 2016. A first look at mobile internet use in township communities in south africa. Proceedings of the 7th Annual Symposium on Computing for Development (2016), 1-10.

[118] Phokeer, A., Hadzic, S., Nitschke, E., Van Zyl, A., Johnson, D., Densmore, M. and Chavula, J. 2020. iNethi Community Network: A first look at local and Internet traffic usage. Proceedings of the 3rd ACM SIGCAS Conference on Computing and Sustainable Societies (2020), 342-344.

[119] Pimmer, C., Brysiewicz, P., Linxen, S., Walters, F., Chipps, J. and Gröhbiel, U. 2014. Informal mobile learning in nurse education and practice in remote areasA case study from rural South Africa. Nurse education today. 34, 11 (2014), 1398-1404.

[120] Plan Intersectorial de Alimentación y Nutrición 2018-2025: Viceministerio de Gobernanza de la Salud Pública: 2018. https://bibliotecapromocion.msp.gob.ec/ greenstone/collect/promocin/index/assoc/HASH01fd.dir/doc.pdf.

[121] Ramachandran, D., Canny, J., Das, P.D. and Cutrell, E. 2010. Mobile-izing health workers in rural India. Proceedings of the SIGCHI Conference on Human Factors in Computing Systems (2010), 1889-1898.

[122] Rey-Moreno, C., Miliza, J., Mweetwa, F., van Stam, G. and Johnson, D. 2016 "Community Networks" in the African Context: Opportunities and Barriers Proceedings of the First African Conference on Human Computer Interaction (2016), 237-241.

[123] Rey-Moreno, C., Sabiescu, A., Siya, M.J. and Tucker, W.D. 2015. Local Ownership, Exercise of Ownership and Moving from Passive to Active Entitlement: A practice-led inquiry on a rural community network. (2015).

[124] Roberts, E.F. 2016. Resources and race: assisted reproduction in Ecuador. Reproductive biomedicine \& society online. 2, (2016), 47-53.

[125] Ruiz, E.C.V. and Sánchez, Á.J. 2019. E-Health in Ecuador: Experiences and Good Practice. 2019 Sixth International Conference on eDemocracy \& eGovernment (ICEDEG) (2019), 92-100.

[126] Sacoto González, L.M. 2006. Ley de maternidad gratuita y muerte materna, provincia del Cañar, 2005-2006.
[127] Sajjad, U.U. and Shahid, S. 2016. Baby+: A mobile application to support pregnant women in Pakistan. Proceedings of the 18th International Conference on HumanComputer Interaction with Mobile Devices and Services Adjunct (2016), 667-674.

[128] Salinas González, M.O. 2014. Complicaciones materno fetales asociados a la Preeclampsia atendidas en el Hospital provincial Isidro Ayora de la ciudad de Loja.

[129] Schwartz, D.A. 2018. Introduction to Indigenous Women and Their Pregnancies: Misunderstood, Stigmatized, and at Risk. Maternal Death and Pregnancy-Related Morbidity Among Indigenous Women of Mexico and Central America. Springer. 3-9.

[130] Secretaría Técnica Planifica Ecuador 2010. Cantón COLTA, Provincia del Chimborazo. Secretaría Técnica Planifica Ecuador.

[131] Sharma, A., Patnaik, R., Garg, S. and Ramachandran, P. 2008. Detection \& management of anaemia in pregnancy in an urban primary health care institution. Indian Journal of Medical Research. 128, 1 (2008), 45

[132] Singh, P.K., Rai, R.K., Alagarajan, M. and Singh, L. 2012. Determinants of maternity care services utilization among married adolescents in rural India. PloS one. 7, 2 (2012), e31666.

[133] Skinner, D., Delobelle, P., Pappin, M., Pieterse, D., Esterhuizen, T.M., Barron, P. and Dudley, L. 2018. User assessments and the use of information from MomConnect, a mobile phone text-based information service, by pregnant women and new mothers in South Africa. BMJ global health. 3, Suppl 2 (2018), e000561.

[134] Smith, W., Wadley, G., Daly, O., Webb, M., Hughson, J., Hajek, J., Parker, A., Woodward-Kron, R. and Story, D. 2017. Designing an app for pregnancy care for a culturally and linguistically diverse community. Proceedings of the 29th Australian Conference on Computer-Human Interaction (2017), 337-346.

[135] Stratton, C. and Nemer, D. 2019. ICTD Research in Latin America: literature review, scholar feedback, and recommendations. Information Technology for Development. (2019), 1-19.

[136] Sultana, S. and Ahmed, S.I. 2019. Witchcraft and hci: Morality, modernity, and postcolonial computing in rural bangladesh. Proceedings of the $2019 \mathrm{CHI}$ Conference on Human Factors in Computing Systems (2019), 1-15.

[137] Sultana, S., Ahmed, S.I. and Fussell, S.R. 2019. "Parar-daktar Understands My Problems Better" Disentangling the Challenges to Designing Better Access to Healthcare in Rural Bangladesh. Proceedings of the ACM on Human-Computer Interaction. 3, CSCW (2019), 1-27.

[138] Sultana, S., Guimbretière, F., Sengers, P. and Dell, N. 2018. Design within a patriarchal society: Opportunities and challenges in designing for rural women in bangladesh. Proceedings of the $2018 \mathrm{CHI}$ Conference on Human Factors in Computing Systems (2018), 1-13.

[139] Swanson, K. 2010. Begging as a path to progress: indigenous women and children and the struggle for Ecuador's urban spaces. University of Georgia Press.

[140] Talhouk, R., Bartindale, T., Montague, K., Mesmar, S., Akik, C., Ghassani, A., Najem, M., Ghattas, H., Olivier, P. and Balaam, M. 2017. Implications of synchronous IVR radio on Syrian refugee health and community dynamics. Proceedings of the 8th International Conference on Communities and Technologies (2017), 193-202.

[141] Talhouk, R., Mesmar, S., Thieme, A., Balaam, M., Olivier, P., Akik, C. and Ghattas, H. 2016. Syrian refugees and digital health in Lebanon: Opportunities for improving antenatal health. Proceedings of the $2016 \mathrm{CHI}$ Conference on Human Factors in Computing Systems (2016), 331-342.

[142] Tausch, A.P. and Menold, N. 2016. Methodological aspects of focus groups in health research: results of qualitative interviews with focus group moderators. Global qualitative nursing research. 3, (2016), 2333393616630466.

[143] Terán, D., Tapia, F., Rivera, J. and Aules, H. 2019. Use of e-Health as a Mobility and Accessibility Strategy within Health Centers in Ecuador with the Aim of Reducing Absenteeism to Medical Consultations. (2019).

[144] Tiwari, P. and Sorathia, K. 2014. Visualising and systematizing a per-poor ICT intervention for Rural and Semi-urban Mothers in India. Proceedings of the 7th International Symposium on Visual Information Communication and Interaction (2014), 129

[145] Tsai, A.C., Tomlinson, M., Dewing, S., Le Roux, I.M., Harwood, J.M., Chopra, M. and Rotheram-Borus, M.J. 2014. Antenatal depression case finding by community health workers in South Africa: feasibility of a mobile phone application. Archives of women's mental health. 17, 5 (2014), 423-431.

[146] Umaefulam, V.O. and Premkumar, K. 2018. Development of text messages for mobile health education to promote diabetic retinopathy awareness and eye care behavior among Indigenous women. International Conference on Smart Health (2018), 107-118.

[147] Vasquez-Cevallos, L.A., Bobokova, J., González-Granda, P.V., Iniesta, J.M., Gomez, E.J. and Hernando, M.E. 2018. Design and technical validation of a telemedicine service for rural healthcare in Ecuador. Telemedicine and e-Health. 24, 7 (2018), 544-551.

[148] Vivar, S.C. 2007. Ecuador addresses cultural issues for pregnant women. The Lancet. 370, 9595 (2007), 1302.

[149] Walburg, V., Friederich, F. and Callahan, S. 2014. Embarrassment and modesty feelings during pregnancy, childbirth and follow-up care: A qualitative approach. Journal of reproductive and infant psychology. 32, 2 (2014), 126-136. 
[150] Walid, N., Noor, N.L.M., Ibrahim, E.N.M. and Ang, C.S. 2016. Potential motivational factors of technology usage for indigenous people in Peninsular Malaysia. 2016 4th International Conference on User Science and Engineering (i-USEr) (2016), 259-264.

[151] Weigel, M.M. and Sanchez, M.E.C. 2013. Ethnic/racial disparities in the fetal growth outcomes of Ecuadorian newborns. Journal of immigrant and minority health. 15, 1 (2013), 198-206.

[152] Wilkinson, S. 1998. Focus groups in feminist research: Power, interaction, and the co-construction of meaning. Women's studies international forum (1998), $111-125$.
[153] World Health Organization 2015. Trends in maternal mortality: 1990-2015: estimates from WHO, UNICEF, UNFPA, World Bank Group and the United Nations Population Division: executive summary. World Health Organization.

[154] World Health Organization 2019. WHO guideline: recommendations on digital interventions for health system strengthening: web supplement 2: summary of findings and GRADE tables. World Health Organization.

[155] Wurtz, H. 2012. Indigenous women of Latin America: unintended pregnancy, unsafe abortion, and reproductive health outcomes. Pimatisiwin. 10, 3 (2012), 271. 